\title{
The effect of vitamin B12 and folic acid supplementation on routine haematological parameters in older people: an individual participant data meta-analysis
}

\author{
Antonia FH Smelt ${ }^{1} \cdot$ Jacobijn Gussekloo ${ }^{1}$. Lynette W Bermingham ${ }^{1} \cdot$ Elizabeth Allen $^{2} \cdot$ Alan D Dangour $^{2}$. \\ Simone JPM Eussen ${ }^{3}$ - Bernard Favrat ${ }^{4}$ Lisette CPGM De Groot $\mathbb{D}^{5} \cdot$ Frans J Kok ${ }^{5} \cdot$ Timothy Kwok $^{6}$. \\ Arduino A Mangoni ${ }^{7} \cdot$ George Ntaios $^{8} \cdot$ Ondine Van De Rest $^{5} \cdot$ Eric Seal $^{9} \cdot$ Paul Vaucher $^{10}{ }^{10}$ Petra Verhoef $^{11}$. \\ Theo Stijnen ${ }^{12} \cdot$ Wendy PJ Den Elzen ${ }^{1,13}$
}

Received: 25 August 2017 / Revised: 28 November 2017 / Accepted: 27 December 2017

(c) Macmillan Publishers Limited, part of Springer Nature 2018

\begin{abstract}
Background/objectives Low vitamin B12 and folate levels in community-dwelling older people are usually corrected with supplements. However, the effect of this supplementation on haematological parameters in older persons is not known. Therefore, we executed a systematic review and individual participant data meta-analysis of randomised placebo-controlled trials (RCTs).

Subjects/methods We performed a systematic search in PubMed, EMBASE, Web of Science, Cochrane and CENTRAL for RCTs published between January 1950 and April 2016, where community-dwelling elderly (60+ years) who were treated with vitamin B12 or folic acid or placebo. The presence of anaemia was not required. We analysed the data on haematological parameters with a two-stage IPD meta-analysis.

Results We found 494 full papers covering 14 studies. Data were shared by the authors of four RCTs comparing vitamin B12 with placebo $(n=343)$ and of three RCTs comparing folic acid with placebo $(n=929)$. We found no effect of vitamin B12 supplementation on haemoglobin (change $0.00 \mathrm{~g} / \mathrm{dL}, 95 \% \mathrm{CI}$ : $-0.19 ; 0.18$ ), and no effect of folic acid supplementation (change $-0.09 \mathrm{~g} / \mathrm{dL}, 95 \% \mathrm{CI}:-0.19 ; 0.01$ ). The effects of supplementation on other haematological parameters were similar. The effects did not differ by sex or by age group. Also, no effect was found in a subgroup of patients with anaemia and a subgroup of patients who were treated $>4$ weeks.

Conclusions Evidence on the effects of supplementation of low concentrations of vitamin B12 and folate on haematological parameters in community-dwelling older people is inconclusive. Further research is needed before firm recommendations can be made concerning the supplementation of vitamin B12 and folate.
\end{abstract}

\section{Background}

The prevalence of anaemia in older persons is high (around $10 \%$ among people aged $\geq 65$ years) and rises with advancing age $[1,2]$. In about one-third of older persons with anaemia co-incidental nutritional deficiencies, such as iron, vitamin B12 and folate deficiency, exist [2]. Among people

Electronic supplementary material The online version of this article (https://doi.org/10.1038/s41430-018-0118-x) contains supplementary material, which is available to authorised users.

Wendy PJ Den Elzen

w.p.j.den_elzen@lumc.nl

Extended author information available on the last page of the article aged $\geq 75$ years, the prevalence of both vitamin B12 and folate deficiency is $>10 \%$ [3-7]. These deficiencies are not only associated with macrocytic anaemia but also with dementia, peripheral neuropathy, combined degeneration of the spinal cord and cardiovascular disease [8-11].

As the prevalence of deficiencies in vitamin B12 and folate are high, screening for deficiencies in vitamin B12 and folate has been recommended as part of a geriatric work-up [12, 13]. Guidelines recommend vitamin B12 supplementation in patients with very low serum vitamin B12 concentrations due to lack of intrinsic factor (IF) (pernicious anaemia) or food-vitamin B12 malabsorption. Several studies have shown significant increases in haemoglobin after vitamin B12 administration in these patients [14-16]. Thus, when low levels of vitamin B12 and 
folate are found, patients are often treated with injections or oral supplements $[9,11,17]$.

Interestingly, evidence of an association between a low serum vitamin B12 concentration and anaemia in older individuals in the general population is limited and inconclusive. Data from the Leiden 85-plus study showed that low vitamin B12 concentrations ( $<150 \mathrm{pmol} / \mathrm{L})$ in 85 -yearold persons are not associated with anaemia [18]. Also, the effect of vitamin B12 supplementation on haemoglobin and mean corpuscular volume (MCV) in elderly with low levels of vitamin B12 is unclear [19].

In contrast to vitamin B12 deficiency, folate deficiency seems to be associated with the presence and the development of anaemia in older individuals [18]. Therefore, early detection of folate deficiency may identify older individuals at risk of anaemia. Preventive folic acid supplementation or folic acid fortification of grain and cereal products has been recommended and has already been initiated at population level in several countries. However, to date, it is not known if older persons benefit from prophylactic folic acid supplementation with regards to haemoglobin levels, as no evidence is available to support this assumption.

In order to evaluate the effect of vitamin B12 and folic acid supplementation on haematological parameters in elderly, we executed a systematic review and individual participant data meta-analysis of randomised placebocontrolled trials.

\section{Methods}

\section{Criteria for considering studies for this meta- analysis}

We considered all randomised controlled trials (RCTs), where community-dwelling elderly $(60+$ years $)$ were treated with vitamin B12 or folic acid (all dosages and all forms of administration) and were compared with elderly who were given a placebo. The presence of anaemia or a vitamin B12/folate deficiency was not required for inclusion. Exclusion criteria were: mean or median age less than 60 years, no availability of haemoglobin concentrations or haematocrit at baseline and during follow-up, combinations of vitamin B12 and folic acid supplementation, and specific populations (e.g., studies in diabetes patients or patients with renal failure).

\section{Search strategy}

We performed a search on PubMed, EMBASE, Web of Science, Cochrane and CENTRAL with relevant MeSHheadings and title words for vitamin B12 and folic acid for randomised controlled trials (RCTs) published between
January 1950 and April 2016. Case reports and letters were excluded. We also searched ClinicalTrials.gov for (ongoing) trials on vitamin B12 or folic acid supplementation in older persons. We also used backward and forward citation screening. The electronic search was performed by an information scientist from the Walaeus Library of the Leiden University Medical Center. The exact search strategy can be found in Supplementary File 1 .

\section{Selection of studies}

All titles and abstracts found in the electronic databases were assessed by the last author. Full copies were acquired of articles that were potentially relevant or in case of uncertainty. WPJdE and LWB appraised these full copies. Disagreement was resolved by consensus. Investigators from each eligible study were invited to join the project and to share their data. The risk of bias of the included studies was assessed using the Cochrane risk of bias assessment table (see Supplemental File 3).

\section{Data collection}

We centrally collected data on demographic characteristics, pre- and post-treatment concentrations of serum vitamin B12, serum/red cell folate, homocysteine, methylmalonic acid, haemoglobin, as well as on levels of haematocrit, mean corpuscular volume (MCV) and red blood cell count (RBC) for all individuals included in the studies. Since vitamin B12 and folate deficiency is defined ideally in terms of serum values of vitamin B12 and folate in combination with homocysteine and methylmalonic acid [8], we also collected data on homocysteine and methylmalonic acid, when available.

\section{Analyses}

We combined the results of the individual studies into two meta-analyses; one on the effect of vitamin B12 supplementation and one on the effect of folic acid supplementation on haematological parameters. We performed a two-stage individual participant data metaanalysis. First, for all individual studies separately, we calculated the mean change in haematological parameters between baseline and follow-up (i.e., follow-up minus baseline) in the active treatment group, and in the placebo group (IBM SPSS Statistics 20). Subsequently, we calculated the difference in mean change (together with its standard error) between the active treatment group and placebo group. Then, pooled estimates for each outcome were calculated using a fixed-effects model, using Review Manager version 5.3.3. The Nordic Cochrane Centre, The Cochrane Collaboration, 2014. We measured statistical 
Fig. 1 Schematic representation of the selection of publications for this meta-analysis

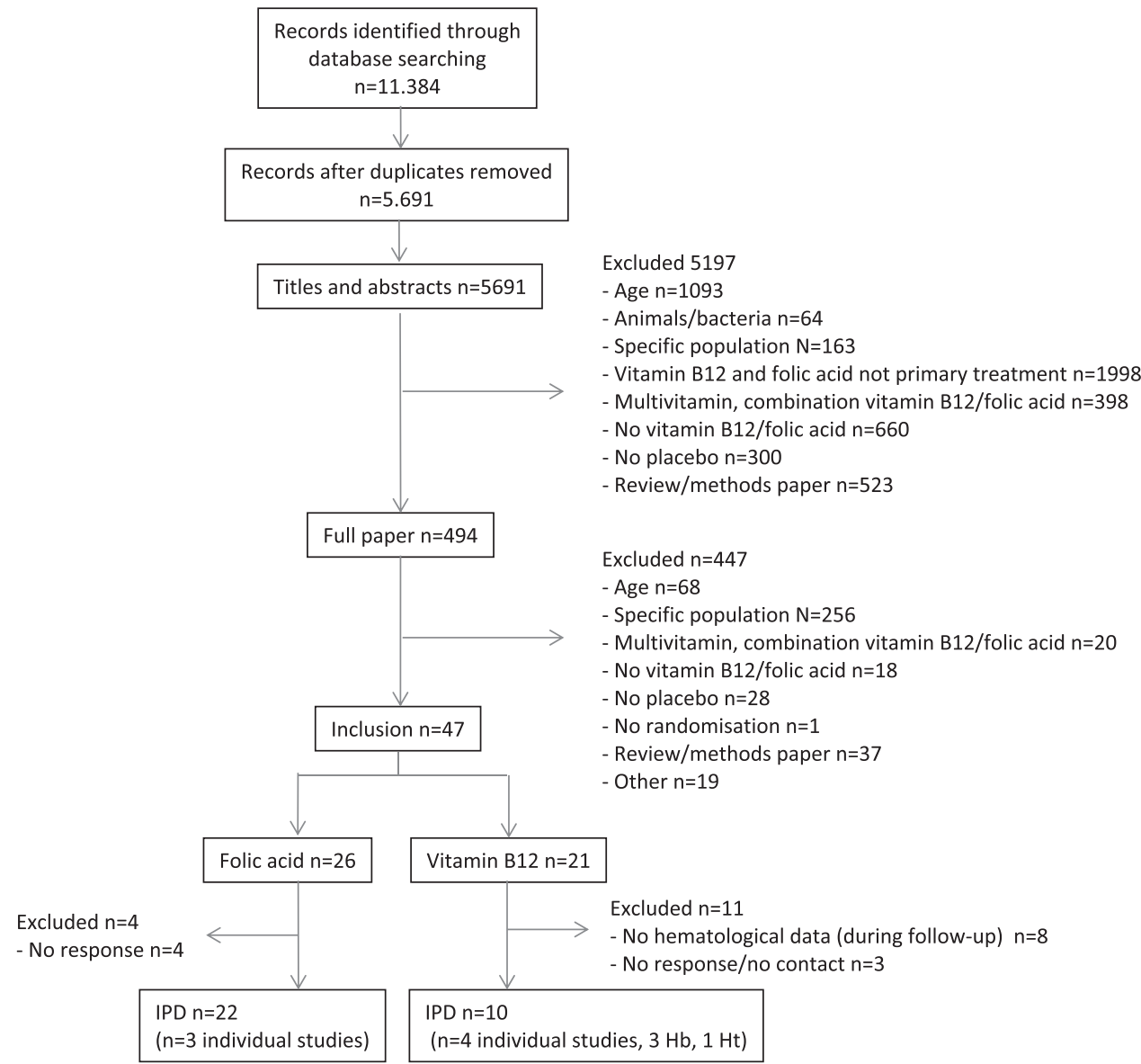

heterogeneity using the $I^{2}$ statistic. An $I^{2}$ value greater than $50 \%$ indicates at least moderate statistical heterogeneity [20].

We performed subgroup analyses for sex and age. Interaction between treatment and sex, and treatment and age, was evaluated by linear regression analysis. Further post hoc analyses were performed in the subgroup of participants with anaemia at baseline, in MCV subgroups, and in studies with a short ( $\leq 4$ weeks) vs. long duration of treatment ( $>4$ weeks).

\section{Results}

\section{Selection of studies}

The electronic search identified 5691 potentially relevant titles and abstracts of papers (performed 25-3-2016). We identified 494 papers, of which 47 fulfilled our inclusion criteria (Fig. 1). Investigators from these studies were invited to join the project and to share their data. Eight authors could not provide haematological data because these were not measured or because individual data were not available anymore. Seven authors did not respond to our request [21-27]. The authors of the other 32 papers $(n=10$ for vitamin B12 and $n=22$ for folic acid) agreed to participate in this project and to share their data on haemoglobin concentrations or haematocrit fractions after supplementation. These 32 papers comprised 4 unique studies on vitamin B12 supplementation [28-31] and 3 unique studies on folic acid supplementation (Table 1) [32-34]. No additional (ongoing) studies were found on ClinicalTrials.gov. The risk of bias of included studies was low (see Supplemental File 3).

Table 1 describes a summary of the characteristics of the included studies. The sample sizes of the included studies varied from ' $n=24$ ' [33] to ' $n=802$ ' [32]. Also, the dosage and the forms of administration and the time to follow-up varied to a great extent (Table 1).

\section{Heterogeneity}

We found no indications for statistical heterogeneity in the studies on vitamin B12 $\left(I^{2}=0 \%\right)$ for all four outcomes, but for the studies on folic acid we found indications for at least moderate statistical heterogeneity $\left(I^{2}=72 \%\right)$ when analysing RBC as an outcome. Also, clinical heterogeneity existed between studies due to different methods of administration, 


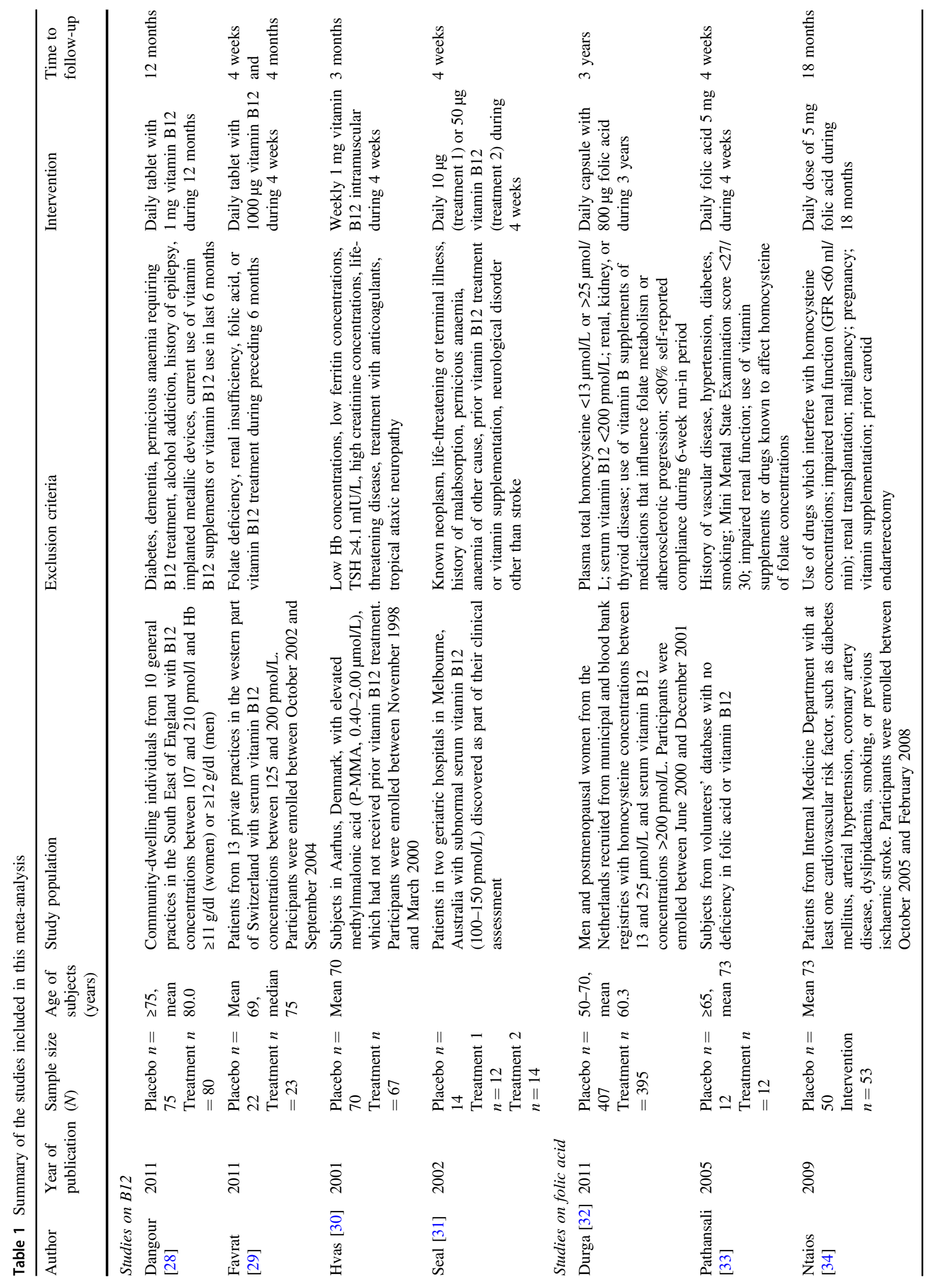


dosage of vitamin B12 and folic acid, outcomes and followup time. Therefore, we show both the results of the individual studies and the results of the pooled effect estimates (Table 2).

\section{Results of analyses}

In Table 2, we show the baseline values of haemoglobin, vitamin B12 and folate. The number of individuals with anaemia was relatively small. None of the individual studies showed a significant effect of vitamin B12 (total $n=343$ ) or folic acid supplementation (total $n=929$ ) on changes in haematological parameters, except for the study by Ntaios on RBC (Table 3). The pooled estimate of the effect on haemoglobin was $0.00 \mathrm{~g} / \mathrm{dL}(95 \% \mathrm{CI}:-0.19 ; 0.18)$ for vitamin B12 supplementation and $-0.09 \mathrm{~g} / \mathrm{dL}(95 \% \mathrm{CI}$ : $-0.19 ; 0.01)$ for folic acid supplementation, meaning that there was no difference in the mean change in haemoglobin concentrations during follow-up between vitamin B12 and placebo, and folic acid and placebo.

In addition, no differences in the mean change in other haematological parameters were observed. For vitamin B12 supplementation, the pooled estimate of the effect was $0.00 \mathrm{~g} / \mathrm{dL}(95 \% \mathrm{CI}:-0 ; 0.01)$ for haematocrit, $0.07 \mathrm{~g} / \mathrm{dL}$ (95\% CI: $-0.58 ; 0.72)$ for $\mathrm{MCV}$ and $0.00 \mathrm{~g} / \mathrm{dL}(95 \% \mathrm{CI}$ : $-0.06 ; 0.06)$ for RBC. For folic acid supplementation, the pooled estimate of effect was $0.00 \mathrm{~g} / \mathrm{dL}(95 \% \mathrm{CI}:-0.01 ; 0)$ for haematocrit, $-0.37 \mathrm{~g} / \mathrm{dL}(95 \% \mathrm{CI}:-0.82 ; 0.08)$ for MCV and $-0.02 \mathrm{~g} / \mathrm{dL}(95 \% \mathrm{CI}:-0.05 ; 0.02)$ for RBC.

\section{Subgroup analyses}

In none of the subgroups on sex and age, a significant effect of vitamin B12 or folic acid supplementation on haemoglobin concentrations was found (Table 4). The effect of vitamin B12 and folic acid on haemoglobin was the same for men and women $\left(P_{\text {interaction }}=0.577\right.$ for vitamin B12 and $P_{\text {interaction }}=0.545$ for folic acid) or between different age groups $\left(P_{\text {interaction }}=0.793\right.$ for vitamin B12 and $P_{\text {interaction }}=$ 0.836 for folic acid). Similar results were found when we repeated the analyses for haematocrit, MCV and RBC (data not shown).

\section{Post hoc analyses}

When we repeated the analyses in participants with anaemia, we did not observe differences in the change in haemoglobin levels between those who were treated with vitamin B12 and those treated with placebo (Table 4). In those treated with folic acid, a significantly larger decline in haemoglobin levels was observed (Table 4). Moreover, when we stratified on MCV $(<80,80-100$ and $>100 \mathrm{fL})$, in none of the subgroups we observed an effect of vitamin B12 or folic acid administration on haemoglobin. In addition, no effect on haemoglobin was found in studies with treatment duration of $\leq 4$ weeks or in studies with a treatment duration of $>4$ weeks, both with vitamin B12 and folic acid (Table 4).

\section{Results from studies without individual participant data}

Of the seven studies that could not be included because of a lack of response from the authors, four studies did not report having measured haemoglobin and/or haematocrit levels. We here discuss the three studies that reported having measured haemoglobin and/or haematocrit levels but of which we did not retrieve data (see Supplemental File 2).

The first study, by Smidt et al., measured haemoglobin and haematocrit at baseline [25], but did not report haematological data at follow-up. The second study, by Hughes et al., measured haemoglobin at baseline and at follow-up [26]. In their study, 93 men and 132 women were given intramuscular hydroxocobalamin $(1000 \mu \mathrm{g}$.), twice in the first week and then at weekly intervals for a further 4 weeks. During their study, there was a small fall in haemoglobin level, but the difference between the mean changes in those given B12 and those given placebo was small and not statistically significant $(0.01 \pm 0.35 \mathrm{~g}$. $)$. In the third study by Rampersaud et al. in 33 healthy, postmenopausal women aged 60-85 years, treatment groups received two different folate repletion intakes (i.e., $\approx 200$ and $\approx 400 \mu \mathrm{g}$ folate/d) [23]. In this study, haematocrit values did not change significantly over the 14-week study period.

\section{Discussion}

In this individual participant data meta-analysis, we did not observe any significant measurable change in routine haematological parameters after treatment with vitamin B12 or folic acid in older persons with either normal or vitamin B12 or folate concentrations below the reference range.

There are several possible explanations for the lack of effect. First, some studies consisted mostly of participants without vitamin B12 or folate deficiency or just below the cutoff values. As these participants may not have had a true tissue deficiency of vitamin B12 or folate, this may have diluted the effect of supplementation. Second, many of the included studies mainly consisted of participants without anaemia. Perhaps haemoglobin levels in non-anaemic patients are less likely to increase in response to vitamin B12 or folic acid treatment than haemoglobin levels in anaemic patients [29]. Unfortunately, the low numbers of people with anaemia refrained us from drawing definite conclusions on the effects of supplementation in an anaemic 
Table 2 Baseline values of haematological parameters and vitamin B12/folate (mean [SD])

\begin{tabular}{|c|c|c|c|}
\hline Author & & Intervention group & Control group \\
\hline \multicolumn{4}{|l|}{ Studies on B12 } \\
\hline \multirow[t]{5}{*}{ Dangour [28] } & Haemoglobin (g/dL) & $14.0(1.1)$ & $13.8(1.2)$ \\
\hline & Haematocrit (fraction) & $41(3)$ & $41(3)$ \\
\hline & Anaemic individuals $(n)$ & 3 of 80 & 10 of 75 \\
\hline & Vitamin B12 (pmol/L) & $232[52]$ & $237[60]$ \\
\hline & B12 deficiency $(n)$ & 3 of 80 & 4 of 75 \\
\hline \multirow[t]{4}{*}{ Favrat [29] } & Haematocrit (fraction) & $40.4(3.9)$ & $39.8(4.6)$ \\
\hline & Anaemic individuals $(n)$ & 10 of 23 & 7 of 22 \\
\hline & Vitamin B12 (pmol/L) & $167(23)$ & $155(20)$ \\
\hline & B12 deficiency $(n)$ & 8 of 23 & 12 of 22 \\
\hline \multirow[t]{4}{*}{ Hvas [30] } & Haemoglobin (g/dL) & $13.1(1.4)$ & $13.5(1.2)$ \\
\hline & Anaemic individuals $(n)$ & 16 of 67 & 12 of 70 \\
\hline & Vitamin B12 (pmol/L) & $303(159)$ & $277[92]$ \\
\hline & B12 deficiency $(n)$ & 1 of 67 & 1 of 70 \\
\hline \multirow[t]{4}{*}{ Seal $[31,1]$} & Haemoglobin (g/dL) & $12.4(1.4)$ & $13.2(1.3)$ \\
\hline & Anaemic individuals $(n)$ & 6 of 12 & 4 of 14 \\
\hline & Vitamin B12 (pmol/L) & $135(27)$ & $143(21)$ \\
\hline & B12 deficiency $(n)$ & 9 of 12 & 7 of 14 \\
\hline \multirow[t]{4}{*}{ Seal $[31,2]$} & Haemoglobin (g/dL) & $13.2(1.7)$ & $13.2(1.3)$ \\
\hline & Anaemic individuals $(n)$ & 4 of 14 & 4 of 14 \\
\hline & Vitamin B12 (pmol/L) & $153[39]$ & $143(21)$ \\
\hline & B12 deficiency $(n)$ & 10 of 14 & 7 of 14 \\
\hline \multicolumn{4}{|c|}{ Studies on folic acid } \\
\hline \multirow[t]{5}{*}{ Durga [32] } & Haemoglobin (g/dL) & $14.2(1.1)$ & $14.3(1.1)$ \\
\hline & Haematocrit (fraction) & $44(4)$ & $44(4)$ \\
\hline & Anaemic individuals $(n)$ & 22 of 395 & 21 of 407 \\
\hline & Folate $(\mathrm{nmol} / \mathrm{l})$ & $12.4(4.3)$ & $12.6(4.6)$ \\
\hline & Folate deficiency $(n)$ & 24 of 395 & 30 of 407 \\
\hline \multirow[t]{5}{*}{ Pathansali [33] } & Haemoglobin (g/dL) & $13.2(0.9)$ & $13.0(0.9)$ \\
\hline & Haematocrit (fraction) & $40(2)$ & $40(2)$ \\
\hline & Anaemic individuals $(n)$ & 3 of 12 & 2 of 12 \\
\hline & Folate $(\mathrm{nmol} / \mathrm{l})$ & $13.8(5.0)$ & $15.0(6.0)$ \\
\hline & Folate deficiency $(n)$ & 9 of 12 & 7 of 12 \\
\hline \multirow[t]{5}{*}{ Ntaios [34] } & Haemoglobin (g/dL) & $13.9(0.7)$ & $14.2(1.2)$ \\
\hline & Haematocrit (fraction) & $42(2)$ & $43(4)$ \\
\hline & Anaemic individuals $(n)$ & 4 of 53 & 2 of 50 \\
\hline & Folate $(\mathrm{nmol} / \mathrm{l})$ & $19.9(8.7)$ & $18.2(6.1)$ \\
\hline & Folate deficiency $(n)$ & 0 of 53 & 0 of 50 \\
\hline
\end{tabular}

Anaemia defined as haemoglobin $<12 \mathrm{~g} / \mathrm{dL}$ (haematocrit $<0.4 \%$ ) for male and $<13 \mathrm{~g} / \mathrm{dL}$ (haematocrit $<0.35 \%$ ) for female individuals Vitamin B12 deficiency defined as B12 $<150 \mathrm{pmol} / \mathrm{l}$

Folate deficiency defined as folate $<7 \mathrm{nmol} / 1$

population with low vitamin B12 or folate concentrations. Third, a low vitamin B12 or folate concentration alone may not be the only reason to develop anaemia, and treatment of these low levels may not be sufficient to raise haemoglobin levels. Other genetic or environmental factors may be involved in the onset of anaemia [19]. Also, other causes such as chronic inflammation may play a role in the development of anaemia [35].

Macrocytic anaemia is one of the most well-known consequences of vitamin B12 and folate deficiency. An elevated mean corpuscular volume (MCV) is often seen as an indication to test for the presence of vitamin B12 or 


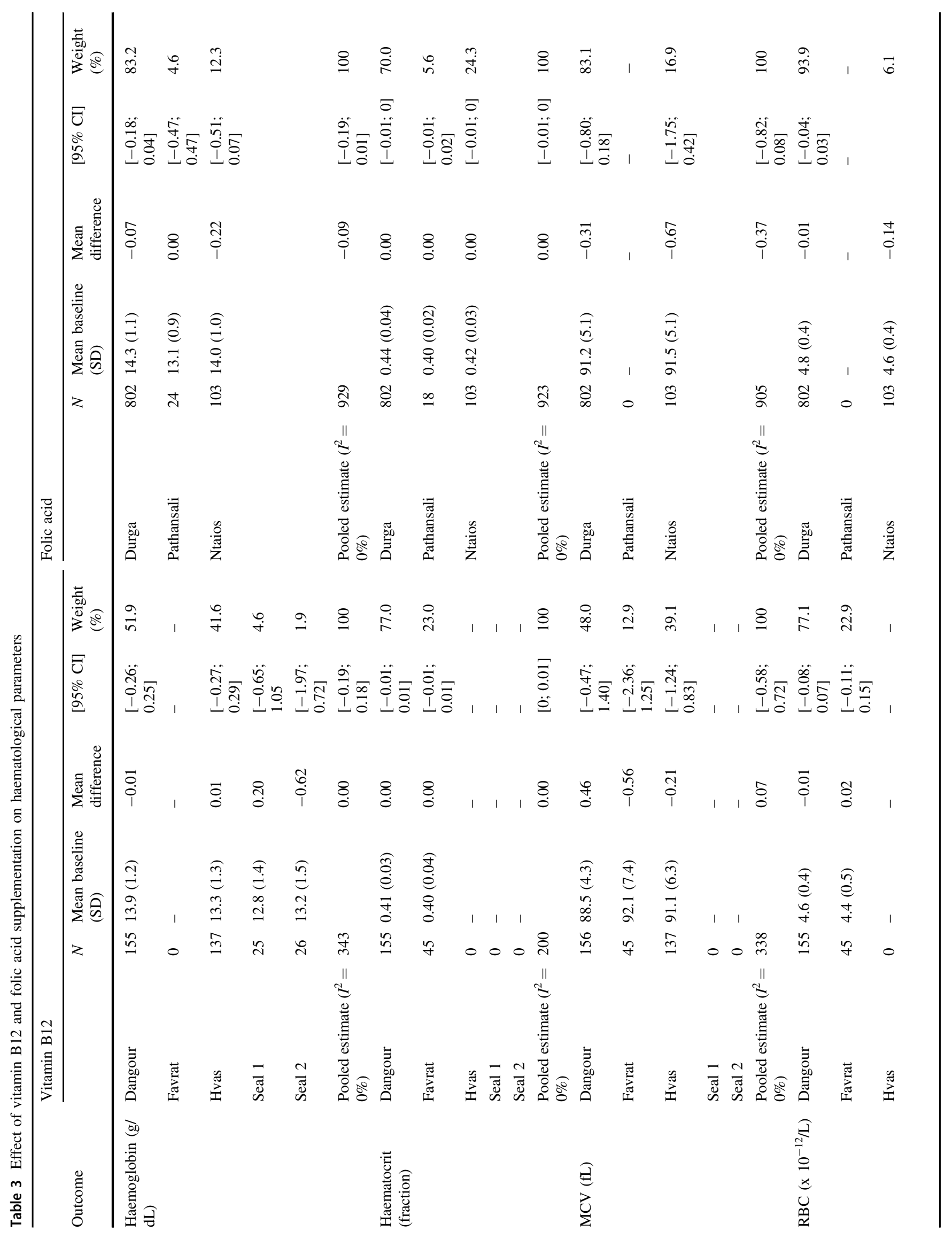




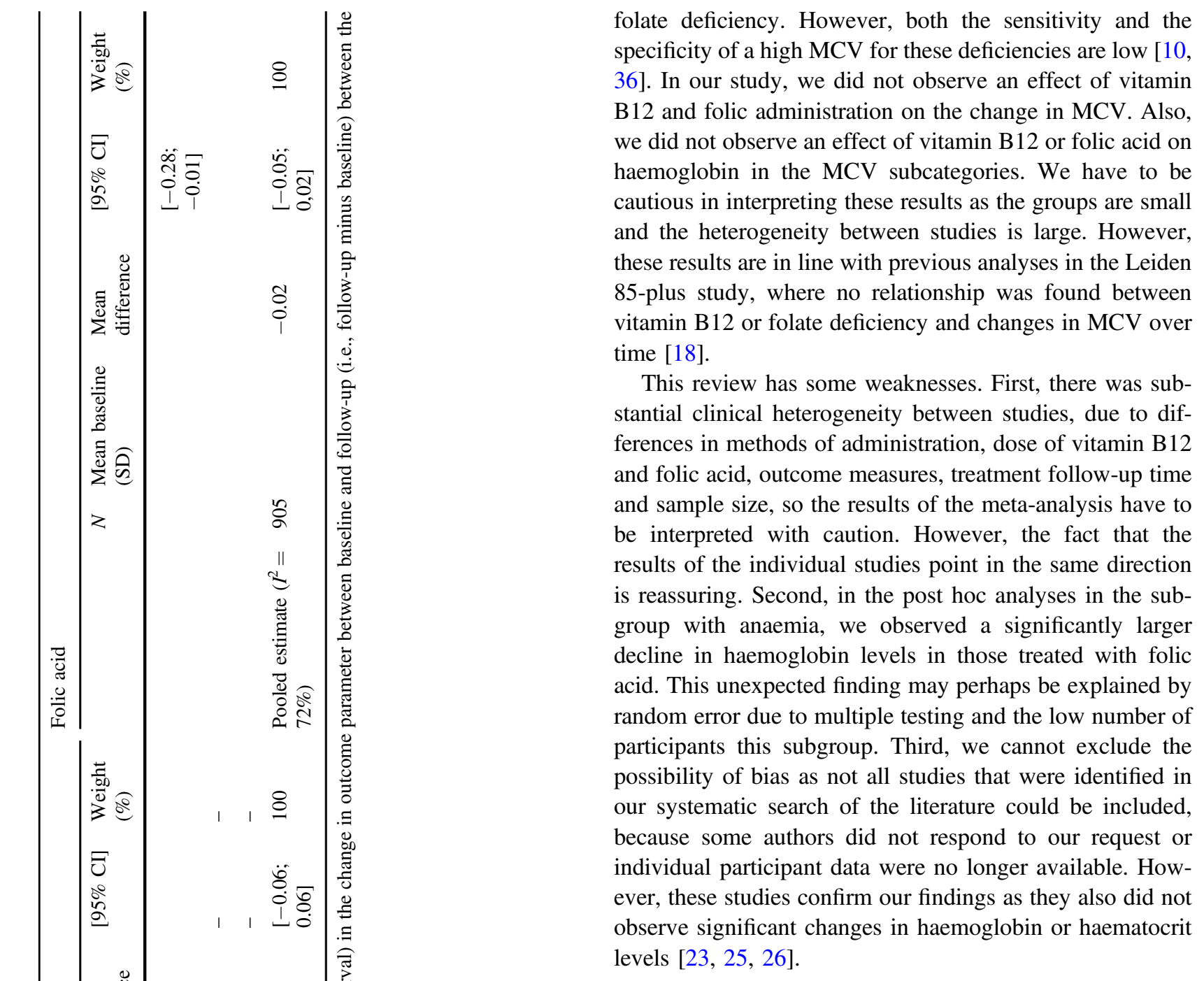

\section{Conclusions}

We did not observe any significant change in routine haematological parameters after treatment with vitamin B12 or folic acid in older persons with either normal vitamin B12 or folate concentrations, or concentrations of vitamin B12 or folate below the reference range. However, we cannot draw firm conclusions because the amount of studies was low, relatively few individuals with anaemia could be included, and the clinical heterogeneity between studies was substantial. Furthermore, we cannot draw conclusions on other benefits of supplementation of vitamin B12 or folate other than haematological outcomes.

Further, well-designed large studies are required to determine whether vitamin B12 and folic acid supplementation are beneficial for older patients with low vitamin B12 or folate concentrations and anaemia or prophylactic effects of these supplements. 
Table 4 Effect of haemoglobin $(\mathrm{g} / \mathrm{dL})$ depending on gender and age, presence of anaemia and duration of treatment

\begin{tabular}{|c|c|c|c|c|c|c|c|c|}
\hline \multirow[b]{2}{*}{ Outcome } & \multicolumn{4}{|c|}{ Vitamin B12 } & \multicolumn{4}{|c|}{ Folic acid } \\
\hline & $N$ & Mean & {$[95 \% \mathrm{CI}]$} & $I^{2}(\%)$ & $N$ & Mean & {$[95 \% \mathrm{CI}]$} & $I^{2}(\%)$ \\
\hline Total group & 343 & 0.00 & {$[-0.19 ; 0.18]$} & 0 & 929 & -0.09 & {$[-0.19 ; 0.01]$} & 0 \\
\hline \multicolumn{9}{|l|}{ Gender } \\
\hline Men & 142 & -0.12 & {$[-0.45 ; 0.22]$} & 0 & 632 & -0.13 & {$[-0.25 ; 0]$} & 76 \\
\hline Women & 201 & 0.10 & {$[-0.09 ; 0.29]$} & 0 & 297 & -0.05 & {$[-0.20 ; 0.11]$} & 0 \\
\hline$P_{\text {Interaction }}$ & & & 0.577 & & & & 0.545 & \\
\hline \multicolumn{9}{|l|}{ Age (years) } \\
\hline$<60$ & 30 & $0.20^{\mathrm{a}}$ & {$[-0.27 ; 0.66]$} & NA & 396 & $-0.07^{\mathrm{b}}$ & {$[-0.21 ; 0.06]$} & NA \\
\hline $60-69$ & 21 & $-0.64^{\mathrm{a}}$ & {$[-1.70 ; 0.42]$} & $\mathrm{NA}$ & 415 & -0.05 & {$[-0.20 ; 0.10]$} & 45 \\
\hline $70-79$ & 164 & -0.04 & {$[-0.30 ; 0.22]$} & 1 & 107 & -0.16 & {$[-0.48 ; 0.17]$} & 0 \\
\hline$\geq 80$ & 128 & 0.13 & {$[-0.16 ; 0.41]$} & 0 & 10 & $-0.47^{\mathrm{c}}$ & {$[-1.39 ; 0.45]$} & NA \\
\hline$P_{\text {Interaction }}$ & & & 0.793 & & & & 0.836 & \\
\hline Anaemia* & 59 & -0.04 & {$[-0.20 ; 0.13]$} & 0 & 54 & -0.19 & {$[-0.30 ;-0.07]$} & 94 \\
\hline \multicolumn{9}{|l|}{$M C V(f L)$} \\
\hline$<80$ & 6 & NA & NA & NA & 14 & 0.06 & {$[-0.32 ; 0.44]$} & NA \\
\hline $80-100$ & 274 & -0.00 & {$[-0.03 ; 0.03]$} & 0 & 849 & -0.09 & {$[-0.10 ;-0.08]$} & $97 \%$ \\
\hline$\geq 100$ & 12 & -0.34 & {$[-0.90 ; 0.22]$} & NA & 42 & 0.03 & {$[-0.11 ; 0.17]$} & NA \\
\hline \multicolumn{9}{|c|}{ Duration of treatment } \\
\hline$\leq 4$ weeks & 206 & -0.01 & {$[-0.25 ; 0.23]$} & 0 & 24 & 0.00 & {$[-0.47 ; 0.47]$} & NA \\
\hline$>4$ weeks & 292 & -0.00 & {$[-0.19 ; 0.19]$} & 0 & 905 & -0.09 & {$[-0.20 ; 0.01]$} & 0 \\
\hline
\end{tabular}

Data are presented as pooled mean difference (95\% confidence interval) in change in haemoglobin during follow-up between active treatment and placebo group

${ }^{\text {a }}$ Only data on study by Hvas et al. [30]

${ }^{\mathrm{b}}$ Only data on study by Durga et al. [32]

c Only data on study by Ntaios et al. [34

* Anaemia defined as haemoglobin $<12 \mathrm{~g} / \mathrm{dL}$ (haematocrit $<0.4 \%$ ) for male and $<13 \mathrm{~g} / \mathrm{dL}$ (haematocrit $<0.35 \%$ ) for female individuals

Acknowledgements We thank Anne-Mette Hvas and Ebba Nexo for sharing study data for this project. We thank Jan Schoones from the Walaeus Library of the Leiden University Medical Center for constructing and performing the electronic search strategies.

\section{Compliance with ethical standards}

Conflict of interest The authors declare that they have no conflict of interest.

\section{References}

1. Beghe C, Wilson A, Ershler WB. Prevalence and outcomes of anemia in geriatrics: a systematic review of the literature. Am J Med. 2004;116:3S-10S.

2. Guralnik JM, Eisenstaedt RS, Ferrucci L, Klein HG, Woodman RC. Prevalence of anemia in persons 65 years and older in the United States: evidence for a high rate of unexplained anemia. Blood. 2004;104:2263-8.

3. Clarke R, Grimley EJ, Schneede J, Nexo E, Bates C, Fletcher A, et al. Vitamin B12 and folate deficiency in later life. Age Ageing. 2004;33:34-41.

4. Flood VM, Smith WT, Webb KL, Rochtchina E, Anderson VE, Mitchell P. Prevalence of low serum folate and vitamin B12 in an older Australian population. Aust $\mathrm{N}$ Z J Public Health. 2006;30:38-41.

5. Lindenbaum J, Rosenberg IH, Wilson PW, Stabler SP, Allen RH. Prevalence of cobalamin deficiency in the Framingham elderly population. Am J Clin Nutr. 1994;60:2-11.

6. Pennypacker LC, Allen RH, Kelly JP, Matthews LM, Grigsby J, Kaye K, et al. High prevalence of cobalamin deficiency in elderly outpatients. J Am Geriatr Soc. 1992;40:1197-204.

7. Wahlin A, Backman L, Hultdin J, Adolfsson R, Nilsson LG. Reference values for serum levels of vitamin B12 and folic acid in a population-based sample of adults between 35 and 80 years of age. Public Health Nutr. 2002;5:505-11.

8. Andres E, Loukili NH, Noel E, Kaltenbach G, Abdelgheni MB, Perrin AE, et al. Vitamin B12 (cobalamin) deficiency in elderly patients. CMAJ. 2004;171:251-9.

9. Hoffbrand A. Megaloblastic anemias. In: Longo D, Fauci AS, Hauser SL, Jameson JL, Loscalzo J, editors. Harrison's principles of internam medicine. 18 ed. New York, NY: McGraw-Hill; 2012.

10. Snow CF. Laboratory diagnosis of vitamin B12 and folate deficiency: a guide for the primary care physician. Arch Intern Med. 1999;159:1289-98.

11. Wolters M, Strohle A, Hahn A. Cobalamin: a critical vitamin in the elderly. Prev Med. 2004;39:1256-66.

12. Clarke R, Refsum H, Birks J, Evans JG, Johnston C, Sherliker P, et al. Screening for vitamin B-12 and folate deficiency in older persons. Am J Clin Nutr. 2003;77:1241-7. 
13. Stabler SP. Screening the older population for cobalamin (vitamin B12) deficiency. J Am Geriatr Soc. 1995;43:1290-7.

14. Vidal-Alaball J, Butler CC, Cannings-John R, Goringe A, Hood $\mathrm{K}$, McCaddon A, et al. Oral vitamin B12 versus intramuscular vitamin B12 for vitamin B12 deficiency. Cochrane Database Syst Rev. 2005;CD004655.

15. Mooney FS, Heathcote JG. Oral treatment of pernicious anaemia: first fifty cases. Br Med J. 1966;1:1149-51.

16. Andres E, Kaltenbach G, Noel E, Noblet-Dick M, Perrin AE, Vogel T, et al. Efficacy of short-term oral cobalamin therapy for the treatment of cobalamin deficiencies related to food-cobalamin malabsorption: a study of 30 patients. Clin Lab Haematol. 2003;25:161-6.

17. Kolnaar BGM, Pijnenborg L, Van Wijk MAM, Assendelft WJJ, Gans ROB. The standard 'anemia' of the Dutch College of General Practitioners. Ned Tijdschr Geneeskd. 2003;147:2193-4.

18. den Elzen WP, Westendorp RG, Frolich M, de RW, Assendelft WJ, Gussekloo J. Vitamin B12 and folate and the risk of anemia in old age: the Leiden 85-Plus Study. Arch Intern Med. 2008;168:2238-44.

19. den Elzen WP, van der Weele GM, Gussekloo J, Westendorp RG, Assendelft WJ. Subnormal vitamin B12 concentrations and anaemia in older people: a systematic review. BMC Geriatr. 2010;10:42.

20. Higgins JP, Thompson SG, Deeks JJ, Altman DG. Measuring inconsistency in meta-analyses. Br Med J. 2003;327:557-60.

21. Bryan J, Calvaresi E, Hughes D. Short-term folate, vitamin B-12 or vitamin B-6 supplementation slightly affects memory performance but not mood in women of various ages. J Nutr. 2002;132:1345-56.

22. Rydlewicz A, Simpson JA, Taylor RJ, Bond CM, Golden MH. The effect of folic acid supplementation on plasma homocysteine in an elderly population. QJM. 2002;95:27-35.

23. Rampersaud GC, Kauwell GP, Hutson AD, Cerda JJ, Bailey LB. Genomic DNA methylation decreases in response to moderate folate depletion in elderly women. Am J Clin Nutr. 2000;72:998-1003.

24. Keane EM, O'Broin S, Kelleher B, Coakley D, Walsh JB. Use of folic acid-fortified milk in the elderly population. Gerontology. 1998;44:336-9.

25. Smidt LJ, Cremin FM, Grivetti LE, Clifford AJ. Influence of folate status and polyphenol intake on thiamin status of Irish women. Am J Clin Nutr. 1990;52:1077-82.
26. Hughes D, Elwood PC, Shinton NK, Wrighton RJ. Clinical trial of the effect of vitamin B12 in elderly subjects with low serum B12 levels. Br Med J. 1970;1:458-60.

27. Garcia A, Pulman K, Zanibbi K, Day A, Galaraneau L, Freedman M. Cobalamin reduces homocysteine in older adults on folic acidfortified diet: a pilot, double-blind, randomized, placebocontrolled trial. J Am Geriatr Soc. 2004;52:1410-2.

28. Dangour AD, Allen E, Clarke R, Elbourne D, Fletcher AE, Letley L, et al. Effects of vitamin B-12 supplementation on neurologic and cognitive function in older people: a randomized controlled trial. Am J Clin Nutr. 2015;102:639-47.

29. Favrat B, Vaucher P, Herzig L, Burnand B, Ali G, Boulat O, et al. Oral vitamin B12 for patients suspected of subtle cobalamin deficiency: a multicentre pragmatic randomised controlled trial. BMC Fam Pract. 2011;12:2.

30. Hvas AM, Ellegaard J, Nexo E. Vitamin B12 treatment normalizes metabolic markers but has limited clinical effect: a randomized placebo-controlled study. Clin Chem. 2001;47:1396-404.

31. Seal EC, Metz J, Flicker L, Melny J. A randomized, double-blind, placebo-controlled study of oral vitamin B12 supplementation in older patients with subnormal or borderline serum vitamin B12 concentrations. J Am Geriatr Soc. 2002;50:146-51.

32. Durga J, Bots ML, Schouten EG, Grobbee DE, Kok FJ, Verhoef P. Effect of $3 \mathrm{y}$ of folic acid supplementation on the progression of carotid intima-media thickness and carotid arterial stiffness in older adults. Am J Clin Nutr. 2011;93:941-9.

33. Pathansali R, Mangoni AA, Creagh-Brown B, Lan ZC, Ngow GL, Yuan XF, et al. Effects of folic acid supplementation on psychomotor performance and hemorheology in healthy elderly subjects. Arch Gerontol Geriatr. 2006;43:127-37.

34. Ntaios G, Savopoulos C, Karamitsos D, Economou I, Destanis E, Chryssogonidis I, et al. The effect of folic acid supplementation on carotid intima-media thickness in patients with cardiovascular risk: a randomized, placebo-controlled trial. Int J Cardiol. 2010;143:16-9.

35. Nemeth E, Ganz T. Anemia of inflammation. Hematol Oncol Clin North Am. 2014;28:671-81.

36. Oosterhuis WP, Niessen RW, Bossuyt PM, Sanders GT, Sturk A. Diagnostic value of the mean corpuscular volume in the detection of vitamin B12 deficiency. Scand J Clin Lab Invest. 2000;60:9-18.

\section{Affiliations}

\section{Antonia FH Smelt ${ }^{1} \cdot$ Jacobijn Gussekloo ${ }^{1}$ Lynette W Bermingham ${ }^{1} \cdot$ Elizabeth Allen $^{2} \cdot$ Alan D Dangour $^{2}$. Simone JPM Eussen ${ }^{3}$ - Bernard Favrat ${ }^{4}$ - Lisette CPGM De Groot $\mathbb{D}^{5}$ • Frans J Kok ${ }^{5}$. Timothy Kwok ${ }^{6}$. Arduino A Mangoni ${ }^{7} \cdot$ George Ntaios ${ }^{8} \cdot$ Ondine Van De Rest $^{5} \cdot$ Eric Seal $^{9} \cdot$ Paul Vaucher $^{10}{ }^{10} \cdot$ Petra Verhoef $^{11}$. Theo Stijnen ${ }^{12} \cdot$ Wendy PJ Den Elzen ${ }^{1,13}$}

1 Department of Public Health and Primary Care, Leiden University Medical Center, Leiden, The Netherlands

2 Faculty of Epidemiology and Population Health, London School of Hygiene \& Tropical Medicine, London, UK

3 Department of Epidemiology, School for Cardiovascular Diseases - CARIM, Maastricht University, Maastricht, The Netherlands

4 Department of Ambulatory Care and Community Medicine, University of Lausanne, Lausanne, Switzerland
5 Division of Human Nutrition, Wageningen University, Wageningen, The Netherlands

6 Department of Medicine and Therapeutics, Prince of Wales Hospital, The Chinese University of Hong Kong, Shatin, NT, Hong Kong

7 Department of Clinical Pharmacology, School of Medicine, Flinders University, Adelaide, SA, Australia

8 Department of Medicine, University of Thessaly, Larissa, Greece 
9 Royal Melbourne Hospital, The University of Melbourne, Melbourne, VIC, Australia

10 School of Health Sciences Fribourg, HES-SO University of Applied Sciences and Arts Western Switzerland,

Fribourg, Switzerland

11 Unilever R\&D Vlaardingen, Vlaardingen, The Netherlands
12 Department of Medical Statistics, Leiden University Medical Center, Leiden, The Netherlands

13 Department of Clinical Chemistry and Laboratory Medicine, Leiden University Medical Center, Leiden, The Netherlands 